\title{
Flu Epidemics Force versus Virus Type in USA
}

\author{
Edgar Pereira1 ${ }^{10}$, Cecília Rosa $^{2}$ \\ ${ }^{1}$ Department of Mathematics, Universidade Federal do Rio Grande do Norte, Natal, Brasil \\ ${ }^{2}$ Department of Mathematics, UDI-Instituto Politécnico da Guarda, Guarda, Portugal \\ Email: edgar@ccet.ufrn.br, cecirosa@ipg.pt
}

How to cite this paper: Pereira, E. and Rosa, C. (2020) Flu Epidemics Force versus Virus Type in USA. Open Journal of Epidemiology, 10, 158-166. https://doi.org/10.4236/ojepi.2020.102014

Received: April 7, 2020

Accepted: May 4, 2020

Published: May 7, 2020

Copyright $\odot 2020$ by author(s) and Scientific Research Publishing Inc. This work is licensed under the Creative Commons Attribution International License (CC BY 4.0).

http://creativecommons.org/licenses/by/4.0/

\begin{abstract}
We estimate the influenza force according to the virus type in the USA (United States of America) for the season 2010/11 to 2019/20. For these we use the data available from CDC (Centers for Disease Control and Prevention) related to Public Health Laboratory Virologic Age Surveillance and The Burden Estimates presented by CDC yearly.
\end{abstract}

\section{Keywords}

Influenza Force, Virus Types, Age Groups, Estimates, Laboratory Tests

\section{Introduction}

Influenza is a seasonal epidemic and in general occurs in the winter months, which presents more conditions for contagion ([1] [2]). There are two types of Influenza viruses which affect humans, A and B. Type A has subtypes based on the antigens $\mathrm{HA}$ and NA and it has been responsible for the most reported cases until now. In the last 40 or 50 years the types A (H1N1), A (H3N2) and B of influenza viruses have co-circulated globally ([3] [4] [5]). The influenza virus is constantly mutating. This change is classified in antigenic drift and shift. An antigenic drift is a small change, but it is possible that the human antibodies do not recognize it and people become susceptible and get sick again. Otherwise, when antigenic shift occurs a new HA or NA appears and a pandemic can happen, this is what led to the last pandemic in 2009 with a new virus H1N1 ([6] [7] [8]). Considering that it is not easy to avoid the contagion, the most important prevention measure is vaccination ([9] [10]). Countries have their vaccination programs which are updated yearly according to WHO guidelines and the recommendations for northern hemisphere are on March and for southern hemisphere is on September ([11] [12]).

In the north hemisphere, where the subject of this work is focused, the in- 
fluenza season goes from the week 40 of a year to week 10 of the following year (winter months). Although the vaccination does not avoid the seasonal epidemics across the world, it can still protect some part of the population, mainly those that are more susceptible, youngsters, pregnant women and elders.

We study the epidemic force in the USA according to the virus type and for these we used data from the Centers for Disease Control and Prevention (CDC) for the season 2010/11 through 2019/20.

\section{Influenza Force}

In general, when people get any ILI (Influenza-Like Illness) symptoms, they do not seek for assistance at a first moment, and most of the population with mild symptoms recover without medical assistance. In this way, the statistics provided by the sentinel programs or surveillance systems worldwide do not reflect the actual number of influenza infected people. This can be observed in other epidemic diseases, like the recent COVID-19.

The strategy here to estimate the influenza force according the virus type and age group is:

1) to gather the respective percentage rates of influenza positive specimens reported by Public Health Laboratories in USA, available at the CDC site ([13]),

2) to apply these rates to the Burden Estimates of influenza illnesses ([14]),

$3)$ to analyze the age group data available both as the reported cases ([13]) and the burden estimates ([14]). Considering that in [13] the age groups are $(0-4,5$ - 24, $25-64,65+)$ and in [14] are $(0-4,5-17,18-49,50-64,65+)$ and therefore not all age groups match, we define new age groups $(0-4,5-64,65+)$ to present our burden estimates, keeping the focus on the younger cohort (age group 0 - 4) and the elders cohort (age group 65+).

In Figure 1 we have the Burden Estimates of Influenza Illnesses according to [14], we can observe a periodic behavior by the total cases over the years. This report gives an overall account but still it is not possible to estimate the ages classes with more incidence rate per inhabitant, because the respective populations are not considered.

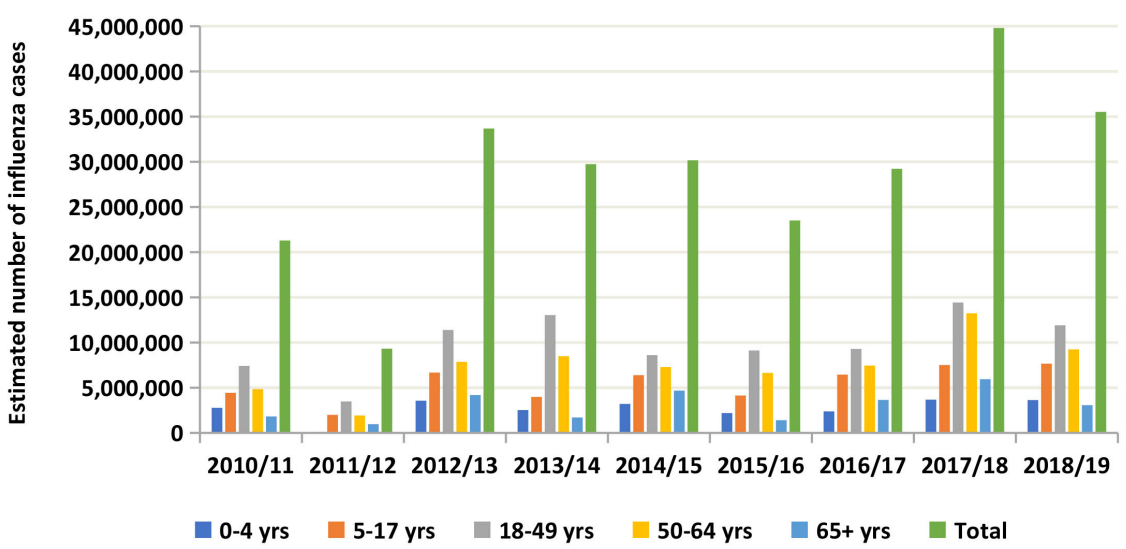

Figure 1. Burden estimates of influenza illnesses in USA, 2010/11-2018/19. 


\section{Virus Type}

The Public Health Laboratory Virologic Age Surveillance is a program of vigilance done by several laboratories ("110 U.S. World Health Organization (WHO) Collaborating Laboratories and 240 National Respiratory and Enteric Virus Surveillance System (NREVSS) laboratories" ([6] [13])), the respective gathering data is presented yearly by CDC ([13]). Although the analyzed specimens are only a small part of the burden estimate of all infected people with influenza in USA yearly, its percentage distribution by age group and virus type can be applied to the whole population giving a good indicator of the actual total numbers.

In Figure 2 we have the Distribution of Influenza Positive Specimens from $2010 / 11$ to $2019 / 20$ ([13]). By the time this worked was concluded, the 2019/2020 season was not finished, but most part of it had already been considered.

Gathering the information of (1) and (2) we can obtain the total burden estimates and the respective virus type distribution, which is shown in Figure 3. At a first glance we can see that in most of the seasons there is a predominant virus type and that the types $\mathrm{A}(\mathrm{H} 3)$ and $\mathrm{A}(\mathrm{H} 1 \mathrm{~N} 1)$ dominate, with $\mathrm{B}$ (Lineage Unspecified) and $\mathrm{B}$ (Yamagata Lineage) appearing next.

In Figure 4 we have the Burden Estimates by week, where we can observe the peak on December and January, weeks 50-10. It is possible to identify a direct relation between these peaks with the season totals of burden estimates in Figure 1 .

In Figure 5 we have the Distribution of Influenza Positive Specimens by virus type according to the age group. Although, in general for a same season the virus type prevalence is equal for the different age groups, we can observe an interesting behavior which is not equal for each of the age groups. For instance, the virus type $A(\mathrm{H} 3)$ occurrence was more significant for the elders and for the youngers was the virus type $\mathrm{A}(\mathrm{H} 1 \mathrm{~N} 1)$.

In Figure 6 we have the Burden Estimates by virus type according to the age group per 100,000 inhabitants.

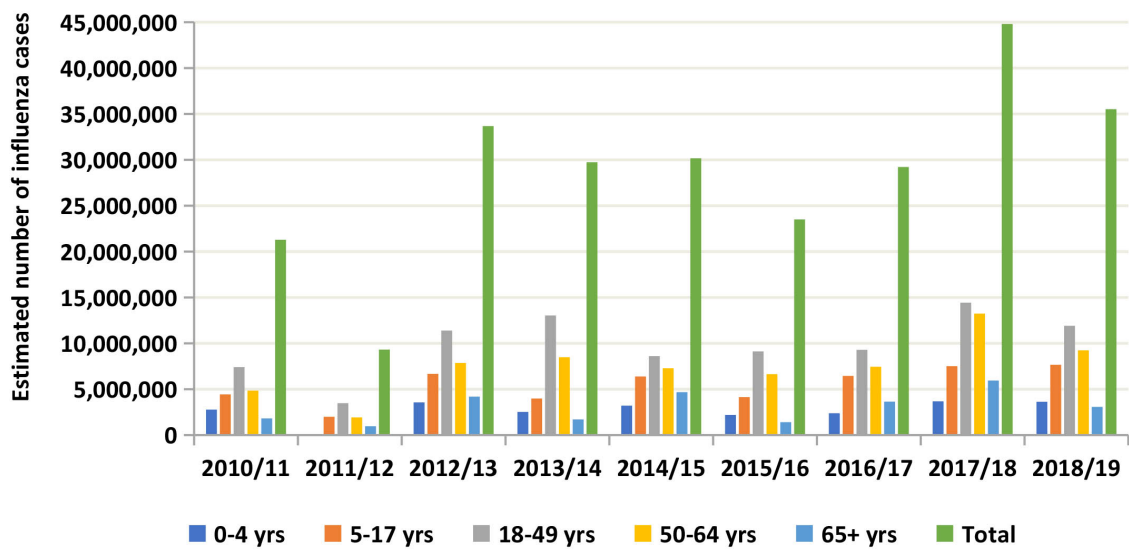

Figure 2. Distribution of influenza positive specimens 2010/11-2019/20. 

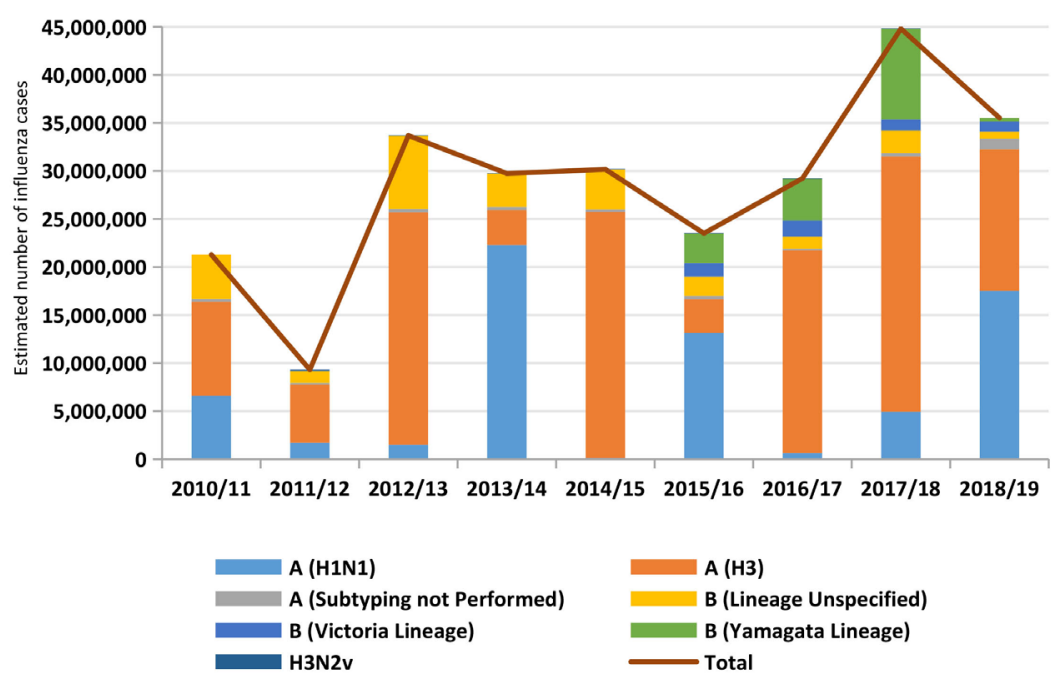

Figure 3. Burden estimates of influenza illnesses by influenza positive specimens 2010/11-2018/19.

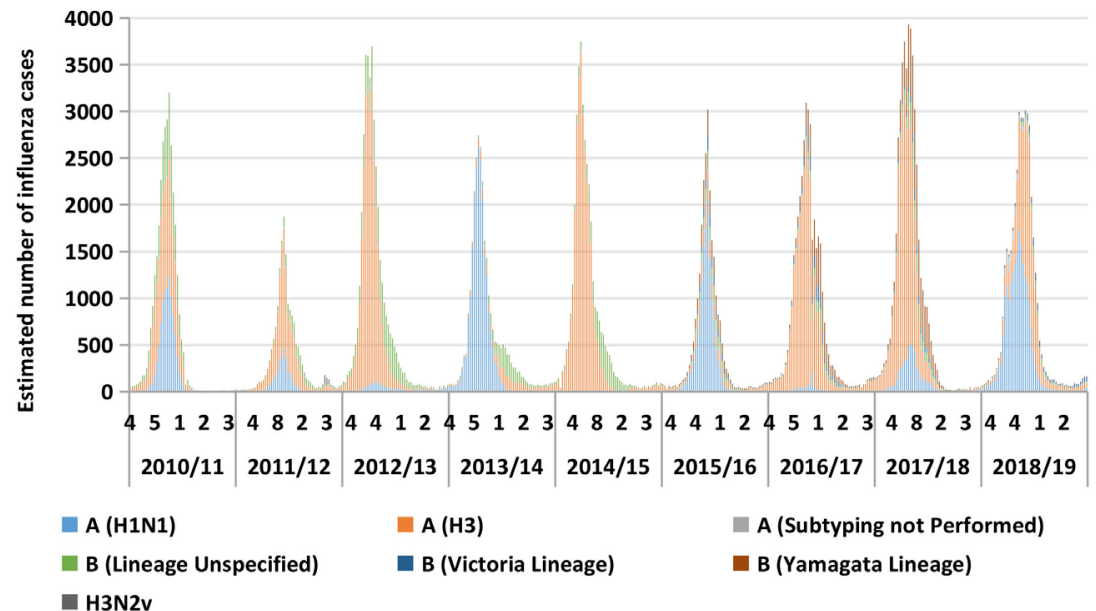

Figure 4. Burden estimates by week 2010/11-2018/19.

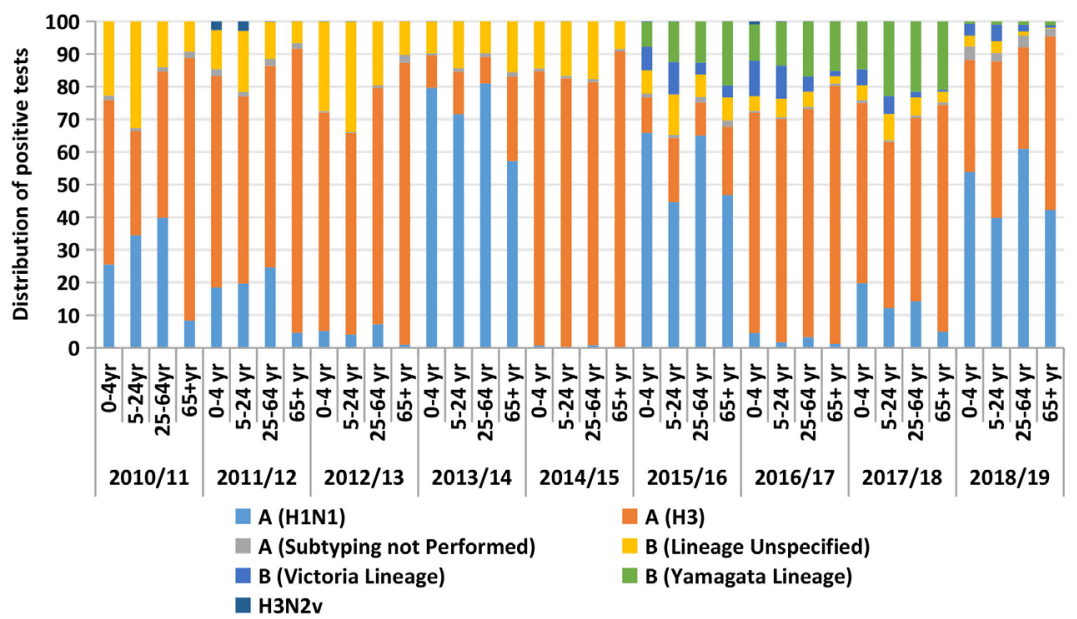

Figure 5. Distribution of influenza positive specimens by virus type according to the Age Group 2010/11-2018/19. 


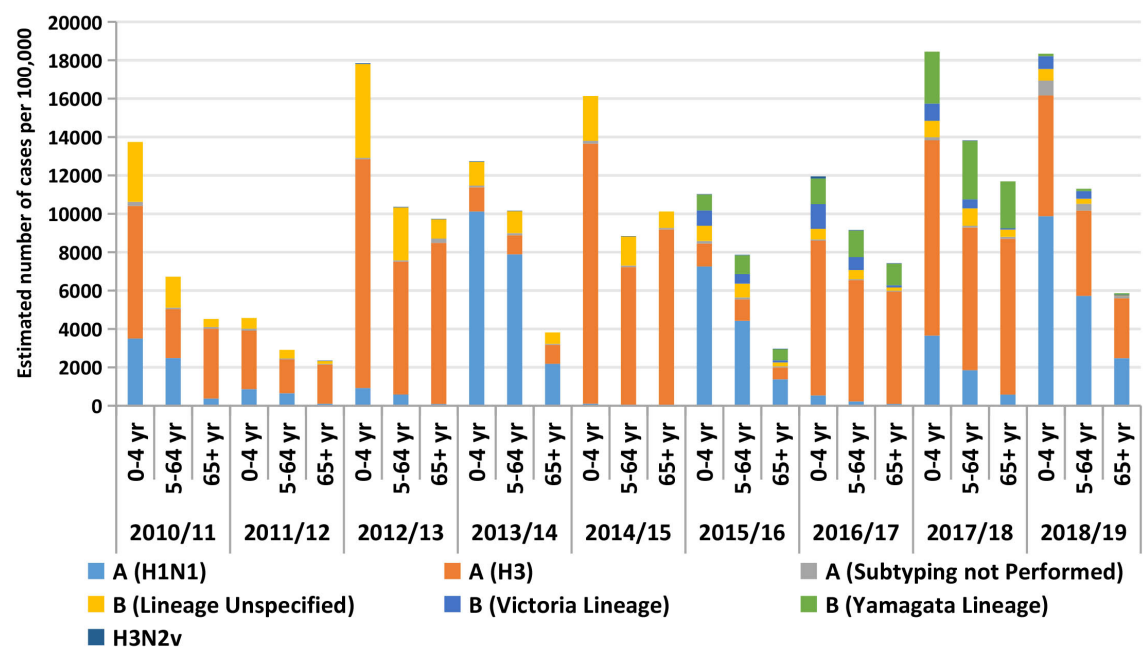

Figure 6. Burden estimates by virus type according to the age group per 100,000 inhabitants 2010/11-2018/19.

Here we observe that higher values occur in the age group $0-4$, and the age group $65+$ is the lowest. This difference in incidence rates probably can be explained by the conscious "social distancing" and even "isolation" of the elders, considering that elderly people know the great risks of getting influenza. We are observing these kind of precaution and care, not only for the elders but for everyone in the current fight against Covid-19.

In Figure 7 we have the Burden Estimates only by the virus type A (H1N1) according to the age group per 100,000 inhabitants.

In Figure 8 we have the Burden Estimates by the virus types A (H3) according to the age group per 100,000 inhabitants.

In Figure 9 we have the Burden Estimates by the virus types A (H1N1) and A (H3) per 100,000 inhabitants.

It can be observed that in general, virus A subtypes compete in a way that there is always one which dominates.

In Figures 10-12 we have the Burden Estimates by the virus types B (Lineage Unspecified), B (Victoria Lineage) and B (Yamagata Lineage), according to the age group per 100,000 inhabitants. We observe a behavior similar to the A types, higher incidence for the youngers and we recall that the vaccination programs also include B types. We do not have the related data for the season 2019/20 yet.

In Figure 13 we have the Burden Estimates for Virus Type A and B, with subtype and lineage not unspecified per 100,000 inhabitants. From the comparison between $\mathrm{A}$ and $\mathrm{B}$ virus types, we can observe that $\mathrm{A}$ type has the dominance.

\section{Conclusion}

We presented the incidence of influenza disease in USA for the seasons 2010/11 through 2019/20. We analyzed several graphs according to age groups and virus type. The study of the influenza outbreak according to the virus is an important issue which can be used for works dealing with prevention and control measures. 


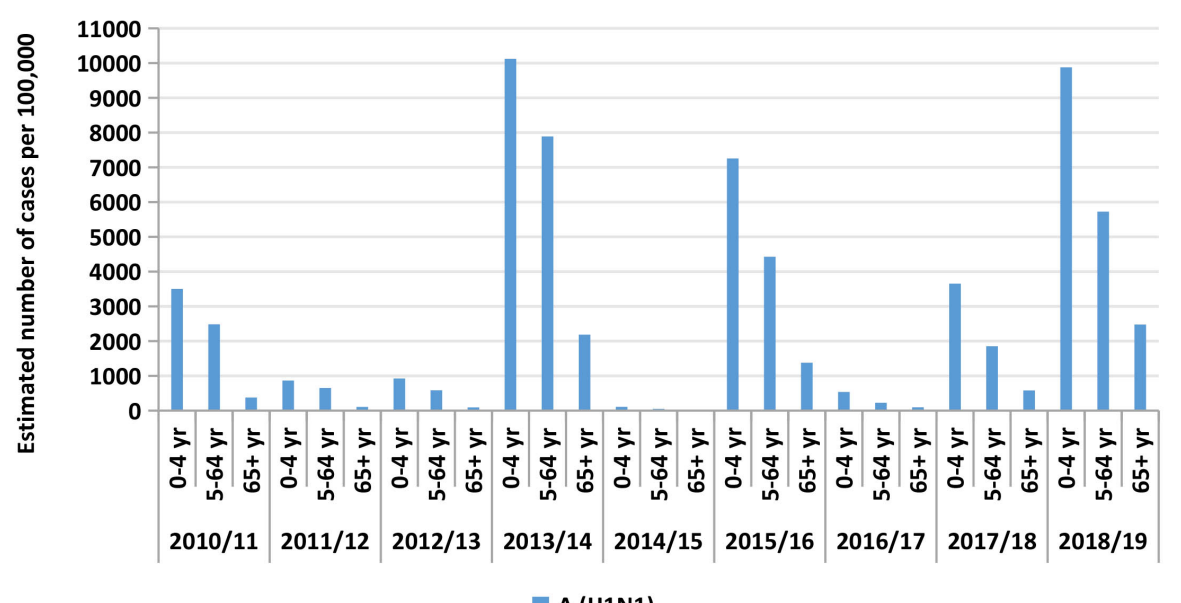

Figure 7. Burden estimates for virus type A (H1N1) according to the age group per 100,000 inhabitants 2010/11-2018/19.

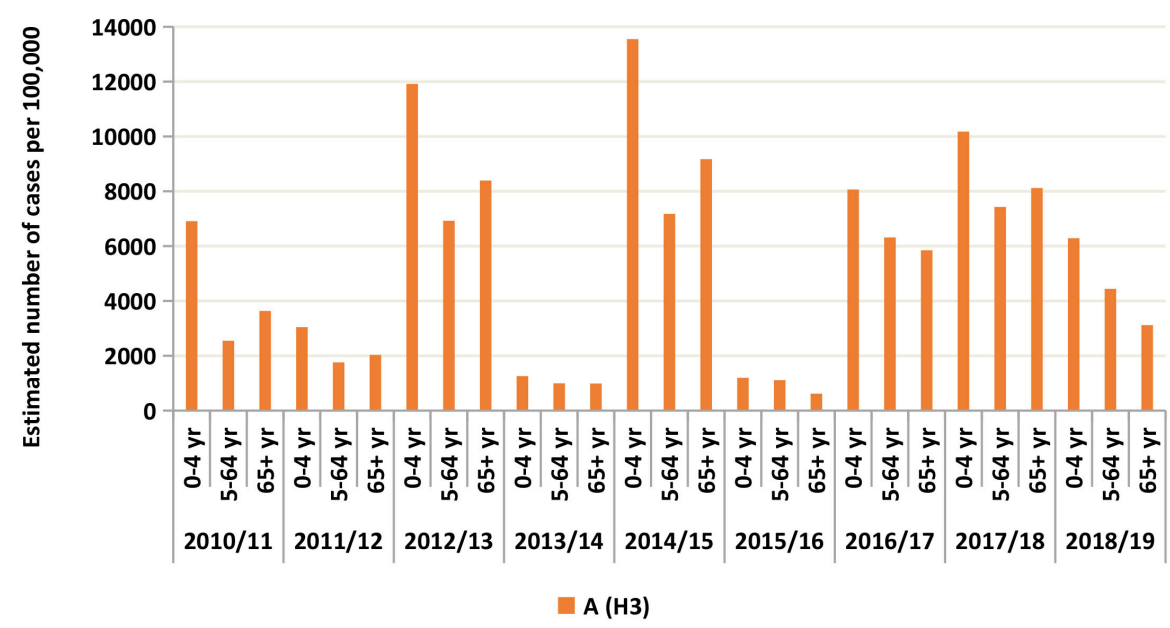

Figure 8. Burden estimates for virus type A (H3) according to the age group per 100,000 inhabitants 2010/11-2018/19.

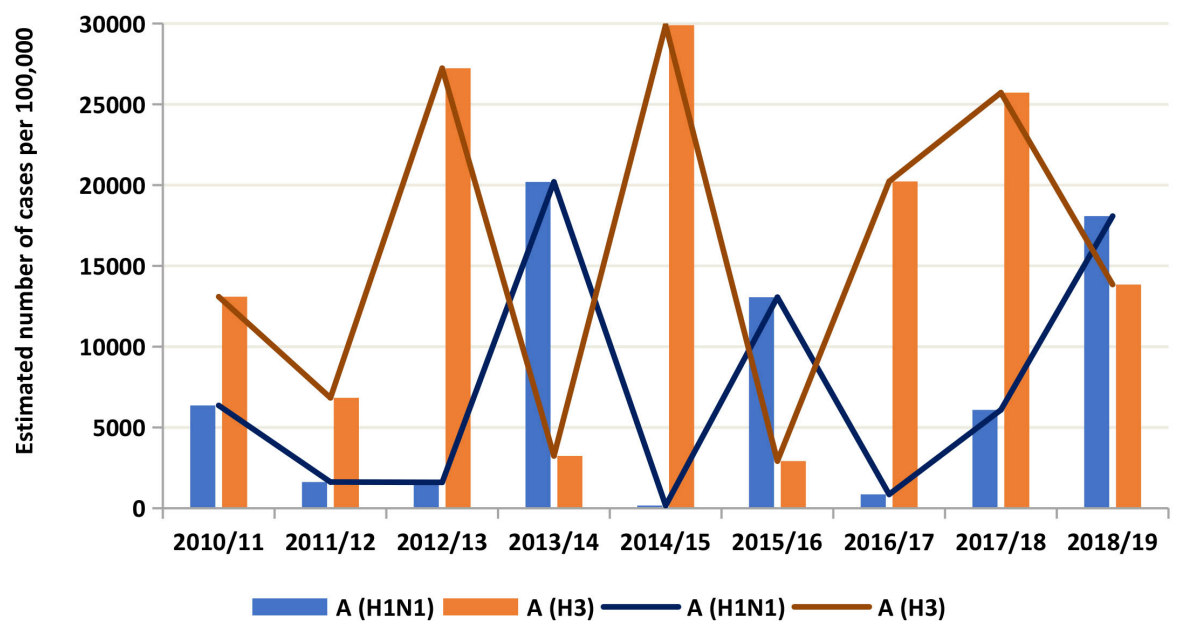

Figure 9. Burden estimates for virus type A (H1N1) and A (H3) per 100,000 inhabitants 2010/11-2018/19. 


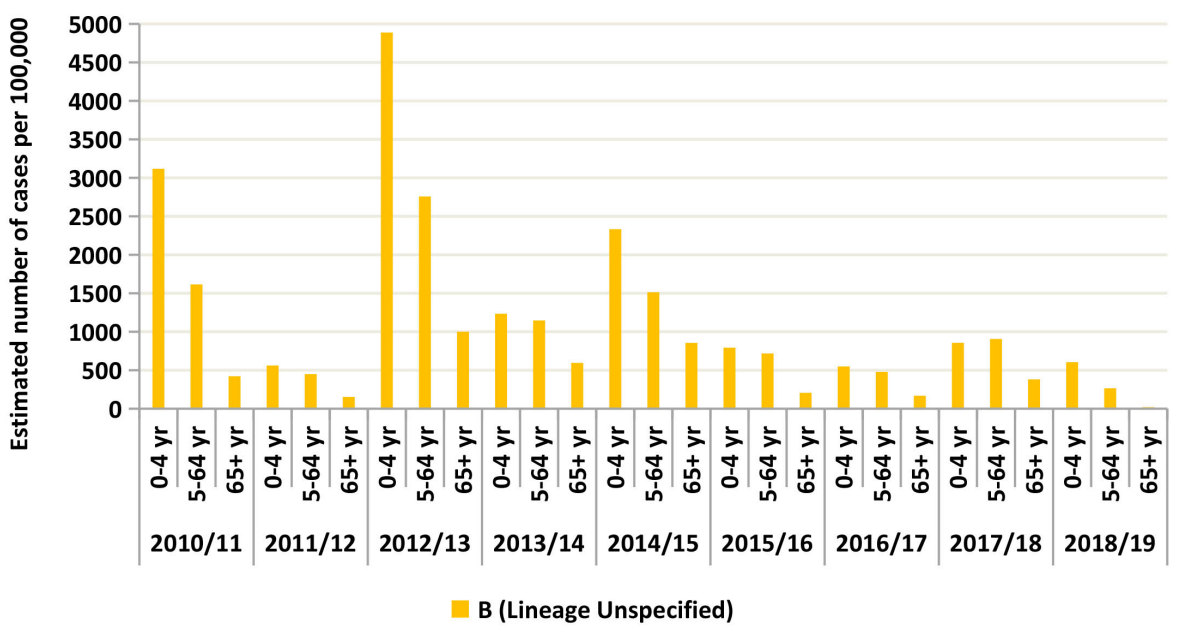

Figure 10. Burden estimates for virus type B (Lineage Unspecified) according to the Age Group per 100,000 inhabitants 2010/11-2018/19.

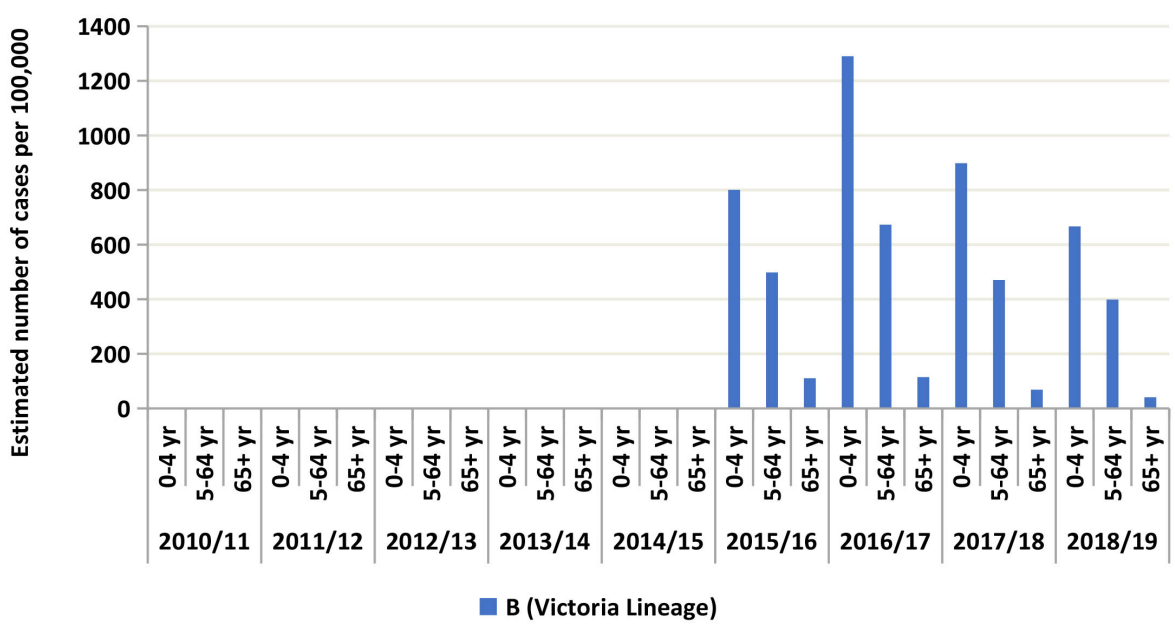

Figure 11. Burden estimates for virus type B (Victoria Lineage) according to the Age Group per 100,000 inhabitants 2010/11-2018/19.

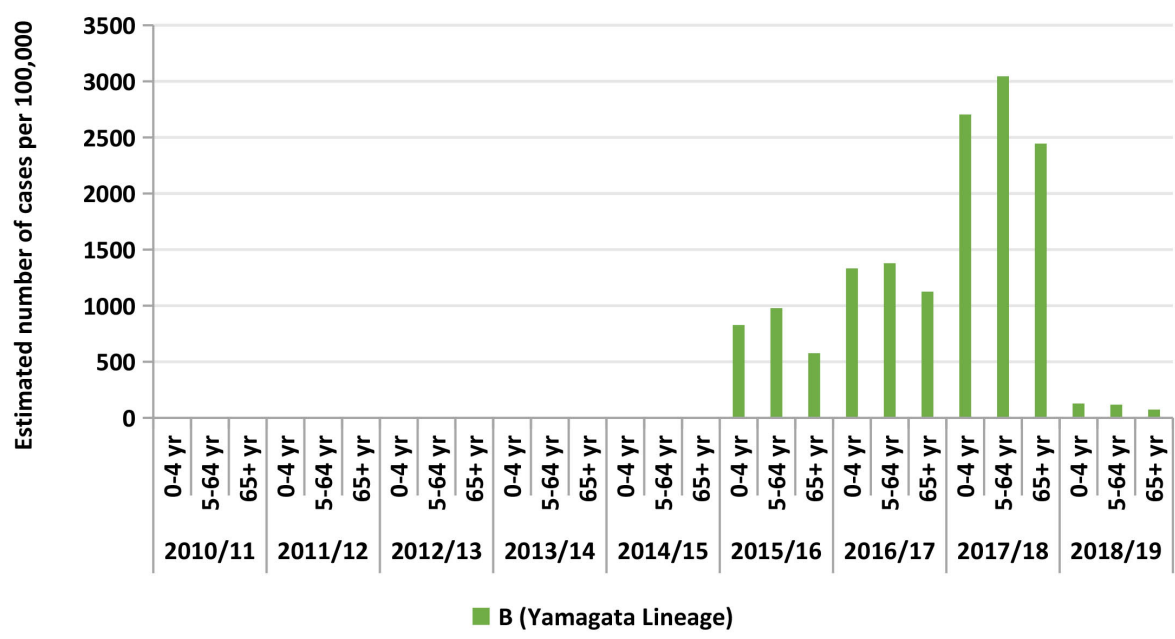

Figure 12. Burden estimates for virus type B (Yamagata Lineage) according to the Age Group per 100,000 inhabitants 2010/11-2018/19. 


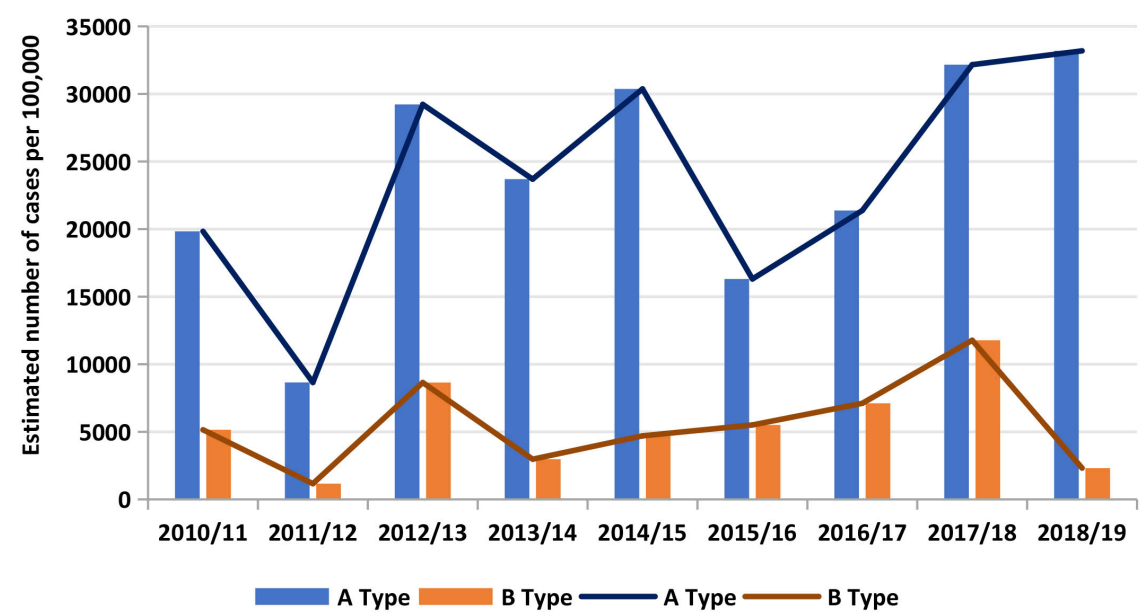

Figure 13. Burden estimates for virus type A and B per 100,000 inhabitants 2010/11-2018/19.

We observed the prevalence of virus type $\mathrm{A}$ and also that the great occurrence appears in age group $0-4$, with the least in the elders, age group $65+$. We hope to extend this study to more regions in the globe.

\section{Acknowledgements}

We would like to thank the anonymous referee for his comments and suggestions.

\section{Conflicts of Interest}

The authors declare no conflicts of interest regarding the publication of this paper.

\section{References}

[1] Hai, A.J., Gregory, V., Douglas, A.R. and Lin, Y.P. (2001) The Evolution of Human Influenza Viruses. Philosophical Transactions of the Royal Society B: Biological Science, 356, 1861-1870. https://doi.org/10.1098/rstb.2001.0999

[2] Van Tam, J. (1998) The Epidemiology of Influenza. In: Nicholson, K.G., Webster, R.G. and Hay, A.J., Eds., Text-Book of Influenza, Blackwell Science, Oxford, 181-206.

[3] CDC (Centers for Disease Control and Prevention) https://www.cdc.gov/flu/about/viruses/types.htm

[4] CDC (Centers for Disease Control and Prevention) https://www.cdc.gov/flu/about/viruses/change.htm

[5] CDC (Centers for Disease Control and Prevention) http://www.cdc.gov/flu/weekly/overview.htm\#Viral

[6] CDC (Centers for Disease Control and Prevention) https://www.cdc.gov/flu/about/professionals/genetic-characterization.htm

[7] Treanor, J. (2004) Influenza Vaccine-Outmaneuvering Antigenic Shift and Drift. New England Journal of Medicine, 350, 218-220.

https://doi.org/10.1056/NEJMp038238 
[8] Webster, R.G., Bean, W.J., Gorman, O.T., Chambers and Kawaoka, Y. (1992) Evolution and Ecology of Influenza A Viruses. Microbiological Reviews, 56, 152-179. https://doi.org/10.1128/MMBR.56.1.152-179.1992

[9] Barberis, I., Myles, P., Ault, S.K., Bragazzi, N.L. and Martini, P. (2016) History and Evolution of Influenza Control through Vaccination: From the First Monovalent Vaccine to Universal Vaccines. Journal of Preventive Medicine and Hygiene, 57, E115-E120.

[10] Belongia, E.A., Skowronski, D.M., McLean, H.Q., Chambers, C., Sundaram, M.E. and De Serres, G. (2017) Repeated Annual Influenza Vaccination and Vaccine Effectiveness: Review of Evidence. Expert Review of Vaccines, 16, 723-736. https://doi.org/10.1080/14760584.2017.1334554

[11] WHO (2019) Recommended Composition of Influenza Virus Vaccines for Use in the 2019-2020 Northern Hemisphere Influenza Season.

https://www.who.int/influenza/vaccines/virus/recommendations/2019 20 north/en 1

[12] WHO (2019) Recommended Composition of Influenza Virus Vaccines for Use in the 2020 Southern Hemisphere Influenza Season.

https://www.who.int/influenza/vaccines/virus/recommendations/2020 south/en/

[13] CDC (Centers for Disease Control and Prevention)

https:/gis.cdc.gov/grasp/fluview/flu by age virus.html

[14] CDC (Centers for Disease Control and Prevention) https://www.cdc.gov/flu/about/burden/2010-2011.html https://www.cdc.gov/flu/about/burden/2011-2012.html, https://www.cdc.gov/flu/about/burden/2012-2013.html, https://www.cdc.gov/flu/about/burden/2013-2014.html, https://www.cdc.gov/flu/about/burden/2014-2015.html, https://www.cdc.gov/flu/about/burden/2015-2016.html, https://www.cdc.gov/flu/about/burden/2016-2017.html, https://www.cdc.gov/flu/about/burden/2017-2018.html, https://www.cdc.gov/flu/about/burden/2018-2019.html, https://www.cdc.gov/flu/about/burden/2019-2020.html 